\title{
Providing Adaptive and Evolving Government E-Services through Citizen-Centric Process Views
}

\author{
Gustav Aagesen and John Krogstie \\ Norwegian University of Science and Technology, Department of Computer and \\ Information Science, Sem Sælandsvei 7-9, NO-7491 Trondheim, Norway \\ \{gustav.aagesen, krogstie\} aidi.ntnu.no
}

\begin{abstract}
As users of government services, citizens spend much of their time in transit between government agencies acting in different roles with varying responsibilities. Government agencies are providers of services virtually connected, but with limited actual integration in practice. We believe that by allowing citizens more direct access to ongoing processes in which they are involved, it could improve service delivery from the perspective of citizen and the government organization alike. In this paper we discuss the concept of citizencentric process views, a conceptual architecture providing channel independent support for knowledge management and monitoring of cross-organizational service delivery in transformational government. We will set the stage for the discussion of requirements for the next generation government infrastructures and the surrounding organizations in order to support delivery of adaptive and evolving government services.
\end{abstract}

Keywords: e-government, services, knowledge management, workflow, evolving IS.

\section{Introduction}

E-government is about the continuous improvement of public administration and service delivery. It is supported through the use of information technology, facilitating the reorganization and development of new services and with the potential of reorganizing the service administration as well.

Services to the citizens are normally provided from government agencies based on what could be understood as an optimal service delivery from point of view of the service provider, and based on historical organization and responsibilities. Individual government agencies deliver services of similar nature to citizens, and the citizens receive combined services from different agencies based on the complexity of the needs of the citizen. From the citizen point of view, orchestration of services appears to be weak, and there is a risk of being caught between uncoordinated service providers.

By connecting services provided to single citizens, new services and service features supporting the potential for increased value of service delivery can be added. Examples include updated information improving expectation management, allowing 
proactive interference and better coordination of compound services, better control with customized services fitted to individual needs, and improved organization of services.

The goal of this paper is twofold: First we discuss the motivation and opportunities of a citizen-centric configuration of service delivery, being aware of that the technical and organizational barriers for citizen access to connected government services are extensive [7, 21]. We further know that providing citizen-centric organization of services require changes in technology, changes that can significantly affect the direction and progress of applications development, by either enhancing or limiting choices or functionality [30]. Based on that we will discuss the possibilities of an adaptive infrastructure and organization supporting delivery of evolving e-services.

In section 2 we provide a background on the current status of e-government service delivery and the motivation of our work. This is followed by a description of the citizen-centric process views, the conceptual architecture, and the discussion of the associated knowledge management scenarios. In the related work section we present research relevant to the functional aspects of the implementation followed by discussion and conclusion.

\section{Background}

Existing stage models for e-government maturity [13, 14, 24] describe the complexity of provided services and the cultural, technological and political prerequisites associated with service delivery on the different stages. The stages depict interactions between government agencies and citizens spanning from the simple availability of online information, to interaction and transaction services and to complex longrunning transactions with multiple actors involved. There is both a cultural and a technological gap between the government service provisioning we see today and that of the transformational government scenario described in literature.

The need for further research on the next generation digital government infrastructures has previously been identified [16, 29]. Research areas include among other building a secure and flexible infrastructure, application areas for service provisioning, establishing business models for the component industry as well as the organizational aspects related to the responsibility of development and maintenance of components. The United Nations has identified three priority areas for future development and the improvement of provided services [28]:

- Making efficiency and effectiveness a reality through high user satisfaction with public services through using IT appropriately to reduce the administrative burdens of citizens and businesses

- Using common platforms to achieve efficiency gains

- Improved interoperability between e-government through the use of e-signatures and electronic identification management.

The 2009 Ministerial Declaration on eGovernment[6] promotes shared European objectives by 2015 including the development of user-centric services that provide flexible and personalized ways of interacting with the public administration. It further 
actively seeks collaboration with third parties, for example businesses, civil society or individual citizens, in order to develop user-driven e-government services.

The future strategy and directions for the development of e-government in Norway includes mapping of standard services and their use of central registries as well as planning access to centrally developed components as common platforms, and the use of e-signatures and electronic identification management.

Altinn II, which is an important part of future information infrastructure in Norway, will among other things support service collaboration and several process owners for cross-organizational processes presented as one integrated process for the users.

User centricity implies that the needs of the different users affect the contents and reach of the services provided. User centricity also involves facilitating for the needs of the individual user in terms of customizing the services offered to that particular user, and taking action to improve the service delivery to all users [8]. Examples of improved service delivery for common good involve extending opening hours and reducing the time spent waiting to be served. Through active collaboration between the central state and municipalities, shared service centers [15] are being developed. This promotes a one-stop government and free citizens from being tossed between governmental offices.

There has been a critique of e-government initiatives taking on a techno-centric, rationalist focus, ignoring the value of organizational learning and knowledge management (KM), and that KM is an important aspect of future government strategies [18]. It is further important that e-government strategies for transformation does not move back to organizational re-engineering and an attempt to 'reinventing government', but promote the development of an ICT strategy that underpins the implementation of organizational change [3].

The work presented in this paper is a part of a study on service provisioning based on the transformational government scenario. Constraining factors of the scenario includes the autonomy of actors, the changing government organizations and policies, the necessary support for process innovation and service reorganization, and the changing requirements of users and systems caused by the availability of new technology affordances.

The 'citizen-centric process views' is a suggested artifact created within a scenario of the next generation government infrastructure. It is based on the idea of a (de-) centralized middleware connecting core components, legacy- and government front office systems for the organization of ongoing and completed instances of provided services to the citizen. It does not provide a user-interface and is in that sense channel independent and extendable through various interfaces. It is a "what if"-scenario, disregarding many cultural, political and technological gaps between the current situation and the envisioned transformational government. At the same time it provides a basis for discussion of the possible utility provided by the technical architecture and the discovery new directions of research.

\section{Citizen-Centric Process Views}

In this section we will present and discuss a potential development of services and service capabilities provided by what we refer to as citizen-centric process views. 
First, we will introduce the main concepts. Then, we will discuss some of the functional capabilities given that the cultural, political, and technological prerequisites for transformational government are met.

\subsection{From Organization- and Service-Centric to Citizen-Centric Service Delivery}

Using Fig. 1, (I) illustrates a traditional understanding of service delivery between a government agency (A) and the citizens (1-N). Each citizen is served directly and service production is centered on the service provider and the isolated service requests. The scenario in the middle (II) provides a shift in focus and places the citizen (X) in the centre of service delivery, and we can see that the citizen interacts directly with several government agencies (A, B, C) although the coordination of the process and service delivery is still left to the citizen.

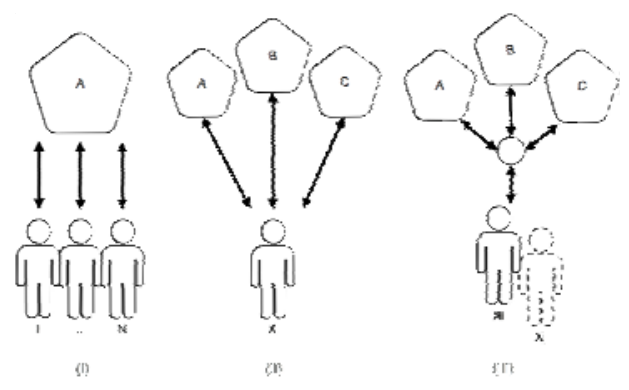

Fig. 1. Service delivery to citizens

The scenario to the right (III) illustrates the conceptual artifact we refer to as a citizen-centric process view: The citizen remains as the main subject, but instead of being the main responsible for coordinating the delivery of services provided, the citizen, government, and non-government agencies are all actors in the choreography of services. These actors are allowed access to review the whole citizen process rather than the individual service stubs in which the process is comprised.

Van der Aalst [33] differentiate enablers of inter-organizational workflows as capacity sharing: Tasks are executed by external resources under the control of one workflow manager, chained execution: The process is divided into subsequent phases and each partner takes care of one phase, subcontracting: A sub-process is executed by another organization, case transfer: Each partner uses the same workflow process and cases are transferred from one partner to another, and loosely coupled: Each partner takes care of a specified part of the process. Regardless of the internal organization of the service provisioning, the current state of the process should be reported to some central artifact in order for the citizen and involved actors to monitor progress, and by doing that support quality assurance.

\subsection{Process Access through Roles}

Central to the citizen-centric process view is the citizen and the different roles the citizen has in its various interactions with the government. It is the roles that initiate 
and require the services, and it is the coordination of the different roles that is important to the citizen. With the roles of a single citizen (Fig. 1, Xi and Xj), come different responsibilities. Some roles might vary depending on the current situation of other citizens related to that particular citizen. The parent role gives access to different services depending on the age and needs of a child, the child role has a different nature when caring for elderly parents and there is a need to take a more active role on behalf of relatives that might not be able to administrate their own rights and responsibilities. Having a certain health condition or being out of work also qualifies for access to particular services. Similarly owning property in different regions might require access to information as well as responsibilities in those regions.

The service providers themselves are not of much importance to the citizen, and the organization and location of government agencies are irrelevant until a service is required. From a citizen point of view, currently utilized services might be chained to connected services located at different providers necessary at a later stage of service provision. Take hospital-services, followed by home-care, borrowing of equipment to support a quick recovery and financial compensation in case of having to be out of work for a longer period. All these services are connected, but provided by different government agencies. The service provider is not important for the citizen, and by connecting the services the citizen will be informed of the required steps and procedures and events. For the government agencies involved in the service provisioning to that particular citizen, the transparency and openness of a channel creates a virtual organization [9] better suited to provide the service efficiently. From the citizen point of view, partly "outsourcing" the coordination of services to a relative or trusted peer as a role in this scenario might serve all involved actors. Alternatively, assigning the support role to a civil servant familiar with the process as responsible for the citizen's interests exclusively, providing online or offline support, will have the potential to compensate for any divide (digital, cultural, etc) the citizen is exposed to.

\subsection{Discovery, Customization and Service Interaction}

By looking at services commonly used in concert, one could use the service connections to discover eligible services based on the role of the citizen or through current service use. This might typically be related to new regulations opening for extra support for citizens in a given situation. Allowing citizens to discover eligible services using current service configuration could provide value to the citizen and increased efficiency in the service distribution from the government side. Connected services are typically found in collections commonly referred to as life-events [27]. Most lifeevent approaches to service discovery are based on semantic models of services rather than information about actual use, involved actors or historical data. There can be situations where information about the services themselves might not be sufficient to provide the necessary information in order to discover complimentary or follow-up services. Using process goals for the citizen in addition to the current services it could be less cumbersome to locate replacement services or to validate whether the current service configuration is the best for the given citizen. This would however require that the involved actors should be granted access to information not necessarily limited to the virtual organization created to support the delivery of a single service. 
Citizen-centricity can involve customizing single services to each citizen's individual needs. This means that the process view should show the actual planned process of the service in which the particular citizen is receiving, including providers, events and other relevant information. This enables proactive behavior from the citizen as well as providers. In the case of the citizen, by merging the workflow for all processes in which it is involved, it is possible to resolve any conflicts that might occur between different services and allow a timely coordination of services.

For some services, it might also be possible for the citizen to interact with the process model and change the order of occurrence, poll status, spin out additional subprocesses, postpone events or cancel ongoing requests. All in all, the interface of the involved actors should invite to a continuous open dialogue between the government and the citizens. The level of process transparency exposed could depend on the requested or necessary involvement of the different actors as well as the nature of the service provided. In its simplest form, the process view provided to the citizen can be limited to a calendar with the planned occurrence of events with event descriptions, deliveries and locations. And for the citizen, some of the bureaucratic elements of a single process might be more confusing than helpful, and might be better left out of the process-view of the citizen.

The implementation of the centralized component is conceptually similar to the functionality of that of a Public Service Broker found in earlier transaction based egovernment initiatives, allowing the citizen to see what government organizations are currently using information about the citizen. The individual user will further have authority over their personal data and can specify what organizations that can access different information [10].

\subsection{Simulation, Monitoring and Forecasting}

From an administrative perspective, the run-time integration of ongoing processes provides an extensive amount of information for monitoring, analysis and policy development. This includes simulating new regulations on actual data, forecasting service demand and discovering possibilities for new services or improved service delivery.

In discovering new process innovations, the need to allow trial and error is one of the aspects of the innovation toolkits introduced by von Hippel [28]. This involves that the user will be allowed to test any changes done to measure the relative improvement of the changes to the artifact, which in our case in most situations will be a process on the instance-level or policy-level. One approach for trial and error on the policy-level has been to extract data from the execution environment, change the rules/regulations or process flow and re-run the process using actual data. This would provide important information to the modeler on how successful a new policy will be based on an isolated and limited dataset. This approach does however have some limitations: First, it is required and assumed that the only those who are eligible and have applied for a service based on the old policy will be within the window of the new policy. Further, any new policy addressing different properties and criteria from previous policies will not be open for simulation, since the properties required will most probably not be within the data available for simulation. There is further only a particular kind of services which are open for such simulation. Human driven 
processes might leave traces of information in the system, and would allow some simulation with respect to breadth and reach of the provided services (i.e. who is eligible, and what outputs exists and the economy of each contact). On the instancelevel this trial and error might prove more fruitful, since one can assume that the user has knowledge of the instance and can supply data relevant to the trial and error simulation. This would involve measuring the process outcomes in form of delay and cost by alternating process flow.

As for government agencies responsible for later steps in the process chains, the forecasting element is based on current active use of services qualifying for entrance to the services provided by that particular provider. The information produced by this forecasting is primarily important to planning and resource management.

\section{Conceptual Architecture}

The conceptual architecture of the citizen-centric process views (Fig. 2 illustrates a part of this) is organized around the delivery of a service to a single citizen. The service comprises of a single or multiple process instances, which contribute to the completion of the service. That is, the process can be the partial delivery of a compound service, a service delivery in a chain of subsequently provided services, or the delivery of a single service. The service defines and organizes the processes where all work is done. The service and processes share the same goals, or the processes partly fulfill the goals of the service.

Each process has a set of actors, which have defined roles in the process. The citizen is the subject who is the receiver of the service produced by the process. There can be several contributors from government and non-government organizations as well as caretakers acting in the interest of the citizen. These actors together form a virtual organization for the service in which the processes are defined. In cases of hand-over of control between different contributors there is always defined a temporary owner of the process responsible for service delivery.

The process is created based on a process template at the time of instantiation. Actors can alter the process either directly if authorized or through change requests (events) that are accepted or rejected by other actors responsible for the process steps that are requested to be changed or affected by the requested changes.

The events contribute to synchronize the current state of the process between all involved actors in the virtual organization. This allows local information systems connected through the system interface to subscribe to events within processes or they can request information about the process. Capabilities defined in the process can be implemented through actors connected to the system interface. This can typically by core components in the national infrastructure or locally defined functionality in the given municipality. This means that the actors interact with the process through a defined system interface, which can be extended to local information systems at the contributors, or to various user devices for caretakers and subjects. The system interface can allow access to custom defined modules running within devices connected through the interface. These can provide various views of the process separately or combined for the different actors. Examples of these are alerts on spending, deadlines, regulations; lookups in central registries for explanations or references; support for 
running what-if scenarios on process changes; process documentation, central reporting, benchmarking or locating similar cases as the given process instance; translation services, or other utilities that prove useful for single actors or the virtual organization as a whole.

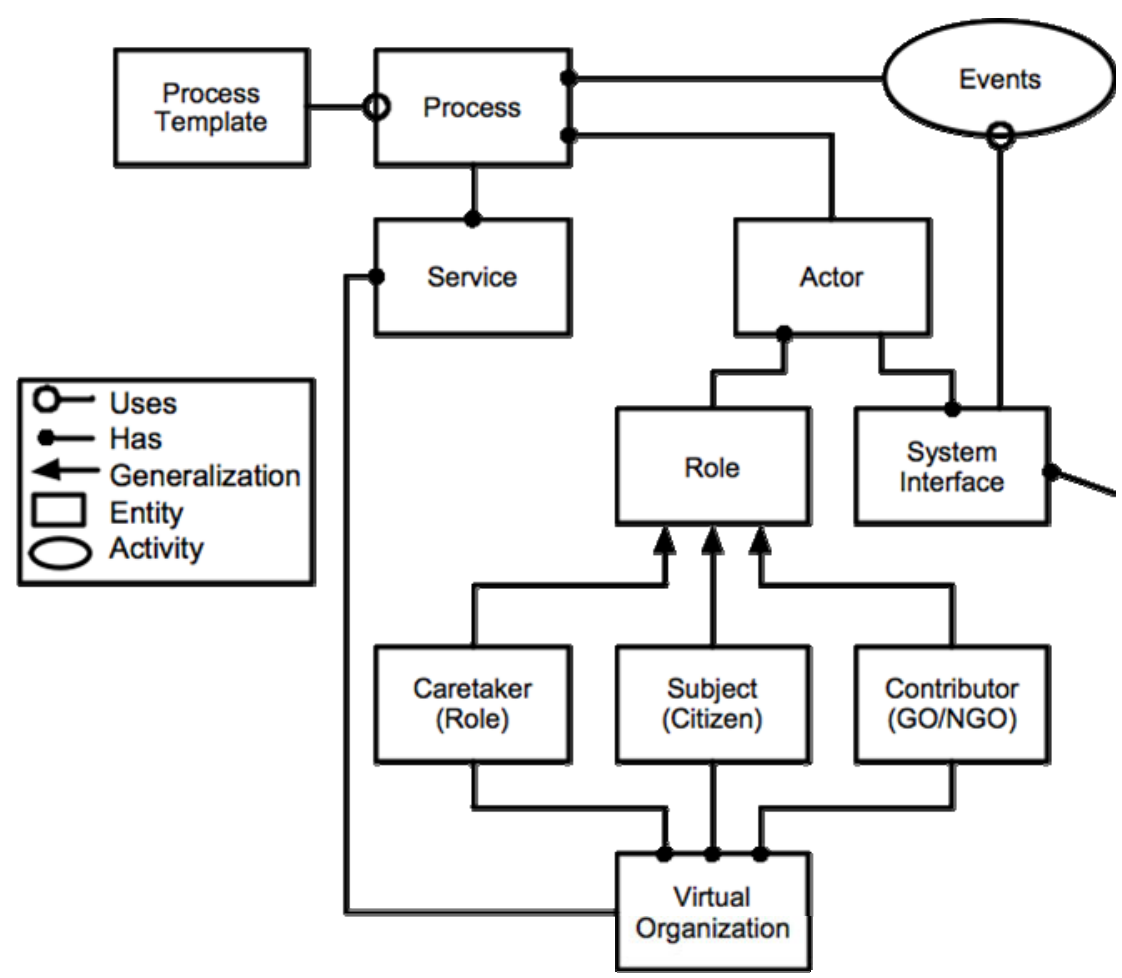

Fig. 2. Conceptual architecture for citizen-centric process views

As we can see from the described conceptual architecture, the citizen-centric process view is a single point of access for the citizen where it can interact with the government on currently provided services. It provides an infrastructure for service collaboration, knowledge management and innovation of service delivery. It supports flexible organization of providers and the different government information systems and with that supports continuous transformation of government services.

\section{Adaptive and Evolving Capabilities}

In the previous section we discussed the conceptual infrastructure of the citizencentric process views. As mentioned, an important aspect is not only to provide services based on a fixed configuration, but also to support service delivery in a transformational government scenario. This requires supporting both dynamic aspects in a static environment, and dynamic aspects in an environment that is dynamic itself. 
This involves changing process instances at run-time, evolving through updating templates, replacing functional components, or redeploying the process as a whole.

The ability to monitor and learn from how the services are provided is one of the utilities of the citizen-centric process views. It enables knowledge creation on the central, local, service and instance level. This further contributes both to making knowledge visible, and promotes knowledge in the organization; it promotes sharing and a knowledge-intensive culture; supports a knowledge infrastructure of technical systems and a web of connections among people given space, time and tools [1].

Changes made to process templates for the running processes can be monitored centrally and locally. Trends can be identified, which can suggest the need for adjusting the process templates. Actual use can further be observed and new policies can be formed for future process executions. At the service level, virtual organizations providing services using similar systems, configurations or acting on similar policies, or municipalities with similar core characteristics (policies, size, budgets, or key-figures) can share experiences and best-practice and in that way co-evolve and share innovations (Fig. 3.). This means that government agencies providing similar services can collaborate on how their process should evolve. They can also share the expenses of improving the systems supporting the process. Having a shared understanding of how services are delivered and a (executable) process description further simplifies the replacement of system components.
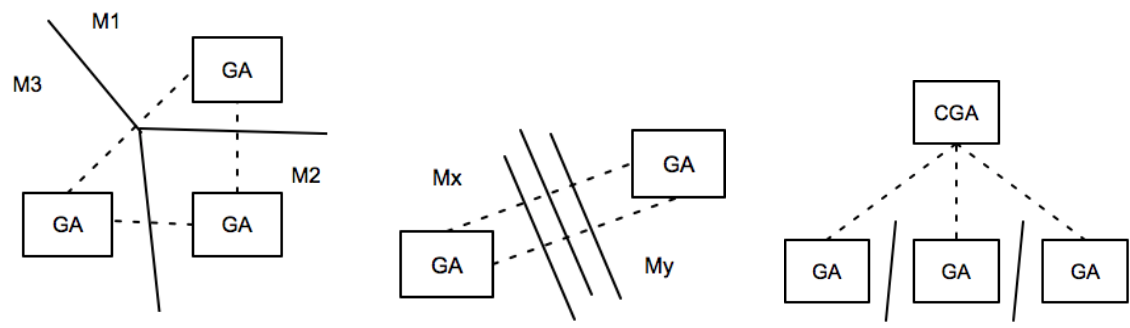

Fig. 3. Co-evolution in virtual organizations or process change coordinated centrally. M: Municipalities; GA: Government Agency; CGA: Central Government Agency.

At the instance level, access to similar scenarios and experiences is functionality the involved actors can benefit from. However, the collaboration of actors and availability of information beyond the isolated task of the single actor is itself a resource that can promote sharing of tacit, individual knowledge of the participating actors and thus improve service delivery.

Using process-mining techniques [33] can also assist the alignment of the formal and actual process, and questionnaire-based pre-process support [32] can help create the process templates and involve the required actors.

\section{Related Work}

There is a gap between currently available technology affordances, organizational culture and political ambitions required to take on the full implementation of the 
scenario presented in the last section. Some of these are disregarded on purpose by our work and are not needed when establishing scenario descriptions or working prototypes. Others are currently addressed and are assumed to receive the proper attention by related work. In this section we will look at current concepts and research that we believe is relevant to our scenario. The relevant work includes architecture principles, work within life-events, enterprise interoperability, commercially available applications and research on dynamically adaptable processes.

\subsection{Organization around Services}

Service Oriented architecture (SOA) is one of the cornerstones to the transformational government infrastructure. "Although SOAs might not be new, they address the fundamental challenges of open systems, which are to operate efficiently and achieve coherence in the face of component autonomy and heterogeneity" [12]. Equally important is the ability to renew, add and remove services dynamically as the requirements of the systems change. Building on the concept of the Enterprise Service Bus, the citizen connects to government agencies and service registries for discovery of services and service interactions. So far, this is similar to the concept of Active LifeEvent Portals [27], aiding service discovery based on the life events of the citizen. Further, Bercic and Vintar [2] suggest allowing agents act on behalf of the citizen as proxies in the interaction with the government. We see that the use of agents to discover eligible services and acting on behalf of the citizen is useful. In the case of citizen-centric process views, using agents as proxies in the virtual organization, responding to the occurrence or non-occurrence of events as one of the application areas. The Norwegian LivsIT project (later named Los) started out as a standardization project for semantic interoperability of public services organized around lifeevents. The life-event focus was later abandoned due to fact that the scope of services related to single life-events is hard to determine. This work is now focused on providing standardization information related to the delivery of single services [5].

\subsection{Inter-organizational Collaboration}

Due to the autonomy of government agencies, obstacles for inter-agency cooperation on the process level occur when the different agencies use different process description languages. Karagiannis and Hofferer [17] have performed a survey looking at the use of meta-models to integrate processed across organizations. Ziemann et al [30] propose a framework to model and transform cross-organizational business processes to technical process model based on web service protocols. The approach involves establishing process descriptions using Event Process Chains (EPC), which is further converted to BPEL syntax.

Holm Larsen and Klischewski [11] discuss the challenges of process ownership in relation to inter-organizational collaboration. They conclude that there is no recipe or guidance available on how to proceed in situations where there is an absence of an overall process ownership or where the overall process ownership is not desired. Punia and Saxena [22] suggest three approaches involving establishing the super-ordinate role, a common shared workspace or interacting through a third party intermediary. Our suggested approach points towards establishing the third party intermediary in the 
custody of the citizen-centric process view, but it is important that the overall process ownership is not left up to the citizen, and that a separate role independent from the agencies providing services take the overall process ownership and the promote the interest of the citizen.

\subsection{Process Modeling and BPM Oriented Tools}

When it comes to the BPM systems, there are several commercially available frameworks. The Itensil dynamic process platform [3] is a solution supporting ad-hoc collaborative process work is different from what found in traditional BPM systems, allowing process change on the fly and version control of individual process instances. Itensil uses a wiki-style framework and AJAX-based user interfaces, supporting effective workspace redistribution. While the Itensil framework is designed for ad-hoc knowledge work in smaller teams, the approach is interesting with respect to large-scale process distribution, innovation and flexibility in government organizations. More traditional BPM-approaches provided in the cloud can be found, e.g. Appian Anywhere ${ }^{1}$ and Cordys Process Factory ${ }^{2}$. Cordys also provides support for more informally defined case-processing systems, but this is so far not available "in the cloud".

Lillehagen and Krogstie [20] describe Active Knowledge Modeling and interactive Models. Models are interactive when they are available to the users at run-time and support automatic synchronization of the execution environment and behavior of the system based on changes to the model made by the user . Active knowledge modelling extends enterprise modeling and focus on the knowledge supporting work through models, methods and tools. Systems can evolve with corporate knowledge and users build and manage their own work environment through model-generated workplaces proving process support and access to relevant information [19]. So far these approaches have not been applied in a transformational government setting.

\section{Discussion and Conclusion}

This paper has introduced the concept of citizen-centric process views for e-government services. The concept is located within work on next generation government infrastructure and the application area for services in the transformational government scenario. It is a (de-)centralized approach connecting core components, legacy- and government front office systems for the organization of ongoing and completed instances of provided services to the citizen. The concept is similar to the one-stop government and active life-events portals where the citizen has online access to discover services. It extends those concepts by focusing on the monitoring, choreography and knowledge management aspects of the actual workflow of ongoing service delivery. The citizencentric process views create a virtual organization around the citizen and the service provided. In contrast to similar concepts, it suggests that there is knowledge about the optimal service delivery present in the virtual organization that is not formalized and therefore preventing the process from being subject to automated processing. This might

\footnotetext{
${ }^{1} \mathrm{http}: / /$ www.appian.com/bpm-saas.jsp

${ }^{2} \mathrm{http}: / /$ www.theprocessfactory.com/
} 
also be due to the fact that the actual services provided are physical or emotional services, and that the process view acts as a documentation and collaboration space for the involved actors. The models used in the process view can be interactive, and changing the workflow model will affect the actors' involvement and actual workflow of the process in question, supporting the evolution of the overall information system.

The citizen-centric process view is one step closer to the recognition of the ecitizen as a separate entity. Traditional government systems identify individuals through references and variables in information system without any binding to the citizen itself. With the process views the citizen will govern information previously not available and which is not controlled by any government agency. Rech Filho [23] suggests that the development of the e-citizen concept might not be a priority interest of the government and that its function might rather be of commercial interest. We believe that the access to government or non-government actors should be open, or at least that it is a political choice rather than technological limitation whether the access should be open or not. In transformational government, government services might just as well be provided through private contractors. On the question of citizencentricity, Kolsaker and Lee-Kelley [18] stresses the fact that "if the needs of the citizens are not understood, provision will be designed around the needs of the state; if the needs of the state are prioritized, e-services will only be used where the needs of the citizens and state coincide".

We observe that a majority of the related work within life-events and one-stop government is relatively old. Some of the suggested life-events frameworks rely on semantic operability and interoperability support not yet mature for large-scale implementation. We believe that our approach is similarly relying on cultural interoperability, but additionally take advantage of the knowledge of the people involved in service delivery, rather than that of formalized information stored prior to service execution. This approach is believed to be more agile and should be able to support a dynamic service configuration and changing systems as a result of changing prerequisites caused by political, technological and regulatory change.

The work so far does not involve a prototype nor does it critically evaluate the concept. We will continue our work on the conceptual model before we can take on the development of any prototype and evaluation within the citizen-centric process views.

\section{References}

1. Alavi, M., Leidner, D.E.: Review: Knowledge management and knowledge management systems: Conceptual foundations and research issues. MIS Quarterly 25(1), 107-136 (2001)

2. Bercic, B., Vintar, M.: Ontologies, web services, and intelligent agents: ideas for further development of life-event portals. In: Traunmüller, R. (ed.) EGOV 2003. LNCS, vol. 2739, pp. 329-334. Springer, Heidelberg (2003)

3. BPMFocus, 'Itensil Dynamic Process Platform', whitepaperv(2008), http: / /bpmfocus.wordpress.com/2008/04/15/ itensil-dynamic-process-platform/ (accessed June 29, 2009)

4. Carlson, J.R., Zmud, R.W.: Channel expansion theory and the experiential nature of media richness perceptions. Academy of Management Journal 42(2), 153-170 (1999) 
5. Elgesem, D.: Lik tilgang for alle. In: Jansen, A., Wiese Schartum, D. (eds.) Elektronisk forvaltning på Norsk, Fagbokforlaget, pp. 355-368 (2008), ISBN 978-82-450-0770-1

6. Minsterial Declaration on eGovernment, 5th Ministerial eGovernment Conference, Teaming up for the eUnion, Malmö (2009), Downloaded from, http: / / www . se2009 . eu /

7. Estevez, E., Janowski, T.: Government-Enterprise Ecosystem Gateway (G-EEG) for Seamless e-Government. In: 40th Hawaii International Conference on System Sciences (2007)

8. FAD, An Administration for Democracy and Community, Report No. 19 (2008-2009) to the Storting, Norwegian Ministry of Government Administration and Reform (2009)

9. Fountain, J.E.: Building the Virtual State: Information Technology and Institutional Change. Brookings Institution Press, Washington (2001)

10. Golden, W., Hughes, M., Scott, M.: The role of process evolution in achieving CitizenCentered e-government. In: Ninth Americas Conference on Information Systems, pp. 801810 (2003)

11. Holm Larsen, M., Klischewski, R.: Process ownership challenges in IT-enabled transformation of interorganizational business processes. In: Proceedings of the 37th Annual Hawaii International Conference on System Sciences (2004)

12. Huhns, M.N., Singh, M.P.: Service-oriented computing: Key concepts and principles. IEEE Internet Computing, 75-81 (2005)

13. Irani, Z., Al-Sebie, M., Elliman, T.: Transaction Stage of e-Government Systems: Identification of its Location \& Importance. In: Proceedings of the 39th Hawaii International Conference on System Sciences (2006)

14. Iyer, L.S., Singh, R., Salam, A.F., D’Aubeterre, F.: Knowledge management for Government-to-Government $(\mathrm{G} 2 \mathrm{G})$ process coordination. Electronic Government, an International Journal 3, 18-35 (2006)

15. Janssen, M., Wagenaar, R.: An analysis of a shared services centre in e-government. In: Proceedings of the 37th Annual Hawaii International Conference on System Sciences (2009)

16. Janssen, M., Chun, S.A., Gil-Garcia, J.R.: Building the next generation of digital government infrastructures. In: Government Information Quarterly. Elsevier, Amsterdam (2009)

17. Karagiannis, D., Hofferer, P.: Metamodeling as an Integration Concept. In: Software and Data Technologies: First International Conference, Icsoft 2006, Setubal, Portugal, September 11-14, pp. 37-49. Springer, Heidelberg (2008) (Revised Selected Papers)

18. Kolsaker, A., Lee-Kelley, L.: Citizen-centric e-government: a critique of the UK Model. Electronic Government 3(2), 127-138 (2006)

19. Krogstie, J., Jørgensen, H.: Interactive Models for Supporting Networked Organisations. In: Persson, A., Stirna, J. (eds.) CAiSE 2004. LNCS, vol. 3084, pp. 550-563. Springer, Heidelberg (2004)

20. Lillehagen, F., Krogstie, J.: Active Knowledge Modeling of Enterprises. Springer, Heidelberg (2008)

21. Papazoglou, M.P., Traverso, P., Dustdar, S., Leymann, F., Krämer, B.J.: Service-oriented computing: A research roadmap. International Journal of Cooperative Information Systems 17, 223-255 (2008)

22. Punia, D.K., Saxena, K.B.C.: Managing inter-organisational workflows in eGovernment services. In: Proceedings of the 6th International Conference on Electronic Commerce, pp. 500-505 (2004)

23. Rech Filho, A.: e-Citizen: Why Waiting for the Governments? In: Böhlen, M.H., Gamper, J., Polasek, W., Wimmer, M.A. (eds.) TCGOV 2005. LNCS (LNAI), vol. 3416, pp. 91-99. Springer, Heidelberg (2005) 
24. Siau, K., Long, Y.: Synthesizing e-government stage models- a meta-synthesis based on meta-ethnography approach. Industrial Management \& Data Systems 105, 443-458 (2005)

25. United Nations, United Nations E-government Survey 2008: From E-government to Connected Governance, Division for Public Administration and Development Management (2007), ISBN 978-92-1-123174-8

26. Van der Aalst, W.: Loosely coupled interorganizational workflows: modeling and analyzing workflows crossing organizational boundaries. Information \& Management 37(2), 67-75 (2000)

27. Vintar, M., Leben, A.: The concepts of an active life-event public portal. In: Traunmüller, R., Lenk, K. (eds.) EGOV 2002. LNCS, vol. 2456, pp. 383-390. Springer, Heidelberg (2002)

28. von Hippel, E.A.: Democratizing Innovation. The MIT Press, Cambridge (2005)

29. Wimmer, M., Codagnone, C., Janssen, M.: Future e-government research: 13 research themes identified in the eGovRTD2020 project. In: Proceedings of the 41st Annual Hawaii International Conference on System Sciences, pp. 223 (2008)

30. Ziemann, J., Matheis, T., Werth, D.: Conceiving Interoperability between Public Authorities A Methodical Framework. In: Proceedings of the 41st Annual Hawaii International Conference on System Sciences, pp. 194-205 (2008)

31. Grant, G., Chau, D.: Developing a Generic Framework for E-Government. Journal of Global Information Management 13(1), 1-30 (2005)

32. Gottschalk, F., Wagemakers, T.A.C., Jansen-Vullers, M.H., van der Aalst, W.M.P., La Rosa, M.: Configurable process models: experiences from a municipality case study. In: van Eck, P., Gordijn, J., Wieringa, R. (eds.) CAiSE 2009. LNCS, vol. 5565, pp. 486-500. Springer, Heidelberg (2009)

33. Van der Aalst, W.M.P., Weijters, A.: Process mining: a research agenda. Computers in Industry 53(3), 231-244 (2004) 